\title{
分析矿山测量在金属矿山安全生产中的运用
}

\section{Analysis of the Application of Mine Survey in Safety Production of Metal Mine}

张小龙 刘金金

\author{
Xiaolong Zhang Xin Liu
}

【摘要】论文就矿山测量在金属矿山安全生产中积极意义、矿山测量工作中的常见问 题、矿山测量在金属矿山安全生产中的运用方面进行了简单分析, 希望对促进中国矿山行 业的发展有所启示和帮助。

彝良驰宏矿业有限公司

中国·云南 昭通 657600

Yiliang Chihong Mining Co.,Ltd.,

Zhaotong, Yunnan, 657600, China
【Abstract】The paper analyzes the positive significance of mine survey in the safety production of metal mines, the common problems in mine survey work, and the application of mine survey in the safety production of metal mines, hoping to provide enlightenment and help for the development of China's mining industry.

【关键词】矿山测量; 安全生产; 积极意义

【Keywords】mine survey; safe production; positive significance

【DOI】10.36012/se.v2i1.1163

\section{1 引言}

矿山测量工作本身就属于一项复杂性较高和实践性较高 的工作, 提高矿山测量工作的效益, 对于实现金属矿山的安全 生产、维护生产人员的生命财产安全等方面有着至关重要的 现实意义。因此, 中国矿山开采行业需要加强对矿山测量工作 的重视, 明确其在测量过程中的常见问题, 从而实现其在金属 矿山安全生产中的更好应用。

\section{2 矿山测量在金属矿山安全生产中的积 极意义}

从宏观角度上来分析，矿山测量是金属矿山安全生产的 前提和基础, 在整个矿山开采过程中占据着重要的地位, 加强 矿山测量工作, 可以为后期的矿山工作计划的编制、施工图纸 的绘制以及安全生产等过程提供完善的数据参考, 在很大程 度上也有利于缩短施工周期, 降低在矿山开采过程中的隐患。

\section{1 为巷道掘进提供指导}

首先, 通过矿山测量工作, 可以为巷道掘进工作提供有效 的数据支持, 促进巷道掘进工作的顺利进行; 其次, 通过矿山 测量工作, 也可以为巷道掘进的施工人员的生命财产安全保 驾护航, 提高巷道掘进施工的安全性和有效性, 避免其在施工 过程中释放大量的有毒气体, 危害人体健康; 最后, 利用矿山 测量工作, 还可以降低施工误差, 提前对巷道掘进的误差进行 分析,并制订相应的措施进行解决。

\section{2 有效降低安全事故的发生率}

矿山在实际的开采过程中, 存在较多的危险因素, 因此, 发生安全事故的概率也较大, 在很大程度上也威胁着施工人员
的生命财产安全和开采企业的社会形象。通过加强矿山测量工 作, 可以对施工现场进行有效的检测, 对于井下巷道的变形情 况进行全面的预测, 从而从源头上降低安全事故的发生率。最 后, 通过矿山测量, 还可以有效预防矿山开采过程中的顶板脱 落问题,避免对正常的矿山开采工作造成影响,延长施工时间。

\section{3 矿山测量工作中的常见问题}

当前, 中国在矿山测量工作中, 还存在着测量设备方面的 问题。中国的矿山测量工作和发达国家相比较, 发展的时间较 晚, 因此, 在一系列的科技以及硬件设施方面还有待完善, 中 国矿山测量工作的效益。受到矿山测量设备上的缺陷, 中国在 具体的矿山测量工作开展的时候, 很容易遭到信号、设备性能 等方面的影响,阻碍测量进程。

\section{4 矿山测量在金属矿山安全生产中的运用}

\section{1 利用矿山测量进行几何定向}

所谓的几何定向主要包含两个部分, 一井定向和两井定 向。其中, 一井定向在实际操作的过程中, 通常情况下, 采取的 都是三角形形式进行连接, 工作人员需要先在矿井上确定临 时点, 然后在矿井下也确定一个相对应的临时点, 两个点和挂 在井筒中的两条垂线之间可以形成一个三角形, 利用对边角 进行观测, 以此来测出井下相应的点坐标和方位角, 进而实现 几何定向; 两井定向在实际操作的过程中,工作人员需要应用 两个立井的情况进行观测, 将两个定井用巷道进行连接, 然后 在每一个立井的井筒中都悬挂一条垂线, 以此来实现井上和 井下的两个方面的观测, 实现几何定向。

(下转第 12 页)
10 2020 年 3 月 
矿山测量 Mine Survey

人员需要提前进行测量工具的相关参数的调试, 对仪器设备 进行检查，保证所有的测量工具都符合实际的矿山井下测量 的需要, 然后方可运输到作业现场。另外, 测量人员还需要加 强对测量工具的养护和维修，及时发现测量工具的问题并进 行解决, 以免影响测量工具的正常使用。第四, 测量人员还需 要应用当前的现代化的测量工具, 加强对新时期下的各种新 型测量工具的学习和了解, 结合矿山的实际需求, 合理选择测 量设备,保证其可以在测量工作中发挥最大的作用,加大测量 设备的资金投人，通过提高测量设备的精确度来提高矿山测 量工作的效率和质量, 并降低测量工作的安全风险 ${ }^{[2]}$

\section{2 综合应用定位技术}

在实际的矿山井下测量工作中，需要严格保证测量工作 的精确度和准确度, 这就需要测量人员在进行矿山井下测量 时, 综合应用定位技术, 以此来满足实际的测量要求。为此, 测 量人员可以使用绝对定位的技术,GPS 技术就是其中较为有 效的一种,测量人员通过应用 GPS 定位技术,可以形成用户 接收天线和对应点的准确定位, 进而实现对相应的测量点的 设计。虽然定位技术在矿山井下测量工作中发挥着至关重要 的作用, 但是, 就目前中国的实际现状来看, 中国对于定位技 术的综合应用的水平还有待提高, 还需要继续优化, 以此来提 高矿山井下测量的精确度。

\section{（上接第 10 页）}

\section{2 利用矿山测量进行陀螺定向}

矿山开采企业还可以利用矿山测量工作完成陀螺定向。 工作人员需要加强对物力定向方式的分析, 利用陀螺仪和经 纬仪进行定向,这种定向方式也被称作陀螺定向,在实际的应 用过程中, 不会对立井的井筒造成影响, 且操作较为简单, 可 以有效避免因为占用井筒导致的停止生产的情况。但是, 就目 前中国矿山测量工作的实际现状来看, 陀螺定向的方式在中 国矿山测量工作中的应用还较少，这是因为其不具备系统性 的操作规程和数据解算方法。

另外, 陀螺定性的应用过程需要涉及陀螺仪和经纬仪等 设备, 其实际应用过程如下: 第一, 工作人员需要在地面上随 意地选择一个点, 确定其比例常数值, 然后再通过六次以上的 观测, 确定三个比例常数值, 取这三个常数值的平均值, 在之 后的很长一段时间内, 这个平均值都可以作为方圆 $50 \mathrm{~km}$ 范 围内的比例常数值进行计算; 第二, 工作人员需要在地面上 确定一个已知边, 并测量陀螺的方位角; 第三, 在返回到地面 以后, 工作人员需要在地面的已知边上测量陀螺方位角。

\section{3 不断提高矿山数据测量质量}

第一, 矿山企业需要重视对测量人员的安排, 对于同一项 工作内容, 企业需要安排 $2 \sim 3$ 名测量人员, 以此来实现测量 人员之间的相互配合, 共同完成矿山井下测量工作; 第二, 在 测量工作完成以后, 企业需要安排专业水平较高的人员对测 量结果进行有效的审核, 保证矿山井下测量数据的质量; 第 三, 测量人员在进行原测点以及相关角度的测量时, 需要先对 测点和角度的布设情况进行分析, 加强对测量误差的控制, 在 进行测量数据的记录时需要保证字迹工整、清晰, 可以准确辨 认,以免出现原始测量数据的错误。

\section{4 结语}

综上所述, 矿山井下测量工作是矿山开采工作的基础和 前提, 在整个矿山开采过程中发挥着重要作用, 因此, 矿山企 业需要加强对矿山井下测量工作的重视, 对于测量过程中的 常见问题进行有效预防, 以此来提高测量工作的质量和效率。

\section{参考文献}

[1]熊军.矿山井下测量常见问题及应对措施[J].低碳世界, 2019,9 (8):75-76.

[2]丁波. 矿山测量常见问题及应对措施探讨[J].世界有色金属, 2019(2):270

\section{3 利用矿山测量确定控制网}

矿山开采企业还可以利用矿山测量工作完成控制网的确 定。第一,工作仍有需要在固定帮的前提下,采取小三角、线形 锁、交会或经纬仪导线方法来实现控制点的确定,然后再使用 经纬仪、平板仪以及摄影等设备完成测量工作, 明确矿区的采 矿场和岩矿石的数量; 第二, 在实际的金属矿山安全生产过程 中, 工作人员需要加强对控制网以及控制点的检查, 综合利用 矿山测量结果的作用, 对控制网布置的误差进行分析, 进行控 制网的调整或者是重新布置; 第三,工作人员还可以利用矿山 测量工作的结果, 为矿山开采提供地形绘制图或者是其他测 量数据, 实现高程测量; 第四, 工作人员还需要在地面上按照 具体的矿山开采要求选择一些定位, 并进行保存, 采取较为精 细的测量方法确定高程控制点,最终形成高程控制网。

\section{5 结语}

在实际金属矿山安全生产中, 矿山测量工作发挥着重要 作用, 可有效提高矿山开采的质量和安全性, 因此, 矿山开采 企业需要加强对矿山测量工作的投入, 保证其测量工作的全 面性,进而促进矿山行业的发展。 